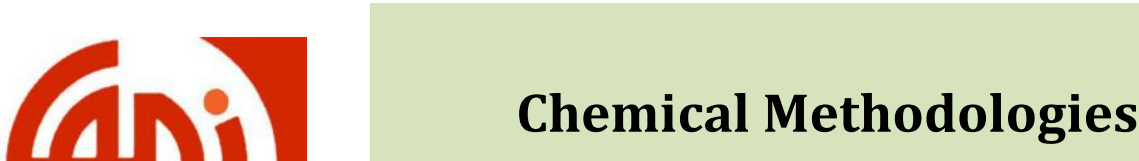 \\ Journal homepage: http://chemmethod.com
}

Review article

\section{Green Chemistry: Principles, Applications, and Disadvantages}

\author{
Wanisa Abdussalam-Mohammed ${ }^{*}$, Amna Qasem Alia, Asma O. Errayes ${ }^{b}$ \\ a Chemistry Department, Faculty of Science, Sebha University, Sebha, Libya \\ b Chemistry Department, Faculty of Science, University of Tripoli, Tripoli, Libya
}

\section{ARTICLE INFORMATION}

Received: 12 October 2019

Received in revised: 05 December 2019

Accepted: 01 January 2020

Available online: 01 July 2020

DOI: $10.33945 /$ SAMI/CHEMM.2020.4.4

\section{KEYWORDS}

Principles of green chemistry

Biodegradation

Catalysis

Waste

Safer chemicals

Disadvantages

\begin{abstract}
This work provides an overview on applicability of 12 principles of green chemistry. Green chemistry is a term that indicates the creation of chemical products and procedures that reduces the use and production of harmful materials. The goals of green chemistry for protecting the environment can be achieved via several main directions. Some of them are bio-catalysis, use of alternative repeatable raw materials (biomass), alternative reaction solution (such as ionic liquids, supercritical fluids, water), alternative reaction circumstances (microwave activation) as well as to new photocatalytic reactions. Moreover, keep natural resources on earth without using harmful materials is the main objective of green chemistry. By changing patterns of consumption and production, steps are being taken to decrease the pollution and harmful waste, which considered being one of the important goals of green chemistry. Also, it was found that, it is so serious to develop alternative technologies that are safer for both human health and the environment to prevent any further damage to human health and the environment such as reducing release of dangerous chemicals to air leading to reduce damage to lungs. In addition, design safer chemical found to be a good opportunity to improve some chemical methods via producing cleaner and cheaper products in industrial processes when harmful chemicals are replacing with biological enzymes. For all the reasons outlined here, in this review, 12 principles of green chemistry are outlined with their applications, where shows how green chemistry reduces the impact of chemical processes on the environment and how their benefit can be achieved. And, also disadvantages of 12 principles are discussed, as well.
\end{abstract}

Copyright (C) 2020 by SPC (Sami Publishing Company)

Chemical Methodologies: $\underline{\text { htp://www.chemmethod.com/ }}$

*Corresponding author: E-mail: Wanisa.mohammed@gmail.com, wani.Ahweelat@sebhau.edu.ly; Chemistry

Department, Faculty of Science, Sebha University, Sebha, Libya, Tel: 00218712635160 


\section{Graphical Abstract}

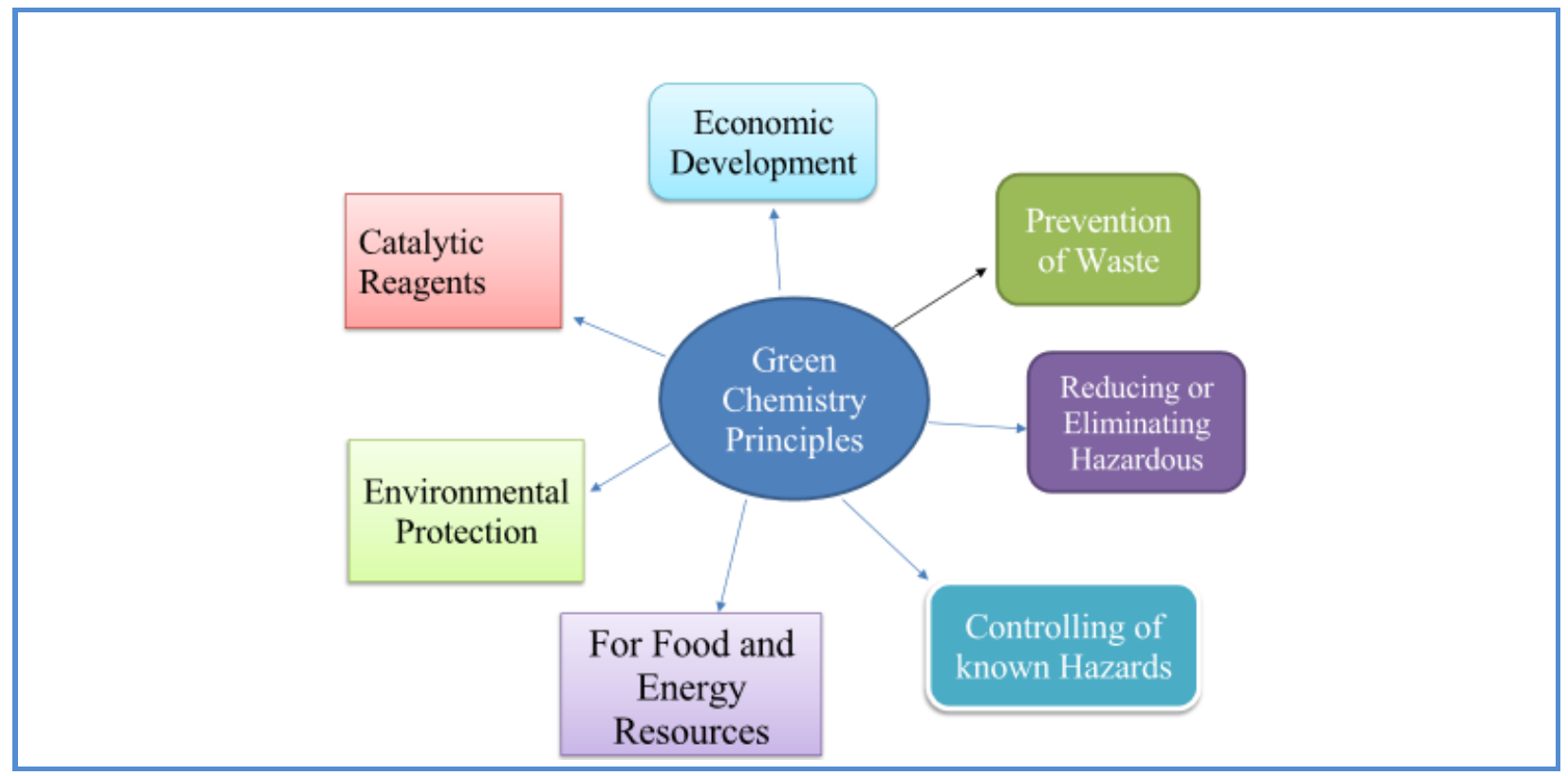

\section{Introduction}

The concept of green chemistry is based on twelve principles that aim at decreasing or removing dangerous materials from the synthesis, production, and application of chemical products, and consequently the use of materials that are dangerous to human health and the environment that should be reduced or eliminated. This concept of green chemistry was first formulated at the beginning of the 1990s. The green chemistry institute founded in 1997 [1] and the publication of the first volume of the well-established green chemistry journal of the royal society of chemistry in 1999 [2, 3]. The twelve principles of green chemistry are design guidelines to help chemists achieving the intentional goal of sustainability. Green chemistry is characterised by careful planning of chemical synthesis and molecular design to reduce adverse consequences. Through proper design one can achieve synergies not just trade-offs [3]. They are used completely chemicals and chemical processes which do not have negative impacts for the environment. It is based on initially generate or recreate molecules, reactions materials, and processes that are safer for both human health and the environment. The processes of the green chemistry include almost all parts of chemistry such as inorganic, organic, biochemistry, polymer, environmental, and toxicology. Through the several prevailing trends of the green program such as catalysis, bio-catalysis and the use of safety alternative: renewable feedstock (biomass), reaction solution (such as water, ionic liquids and supercritical liquids), reaction conditions (microwave irradiation) and new synthetic 
pathways (photocatalytic reaction), the goals of environmental protection and economic benefit can be achieved. This article shows examples of the prevailing trends in ways that green chemistry reduces the impact of chemical processes and technologies on the environment (Figure 1) [4]. Enhanced progress in science and technology in the second half of the twentieth century has led to important economic development and a growth in living standards. While, such economic development has caused considerable environmental degradation, which is demonstrated by more pronounced climate change, the development of ozone holes and the growth of non-destructive organic pollutants in all parts of the biosphere.

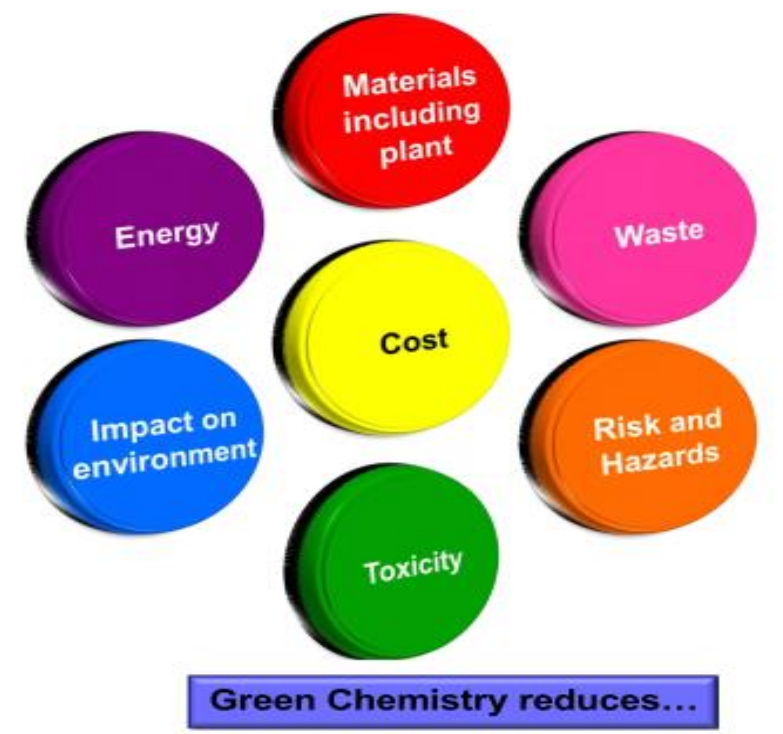

Figure 1. Shows reducers by using green chemistry [4]

The newly established situation needed the search for a solution to balance the use of natural resources, economic growth and environmental protection. Due to the reflections in the last two decades, awareness of the requirement for environmental protection has increased, so great attention is paid to the so-called green and viable technologies. The new laws and regulations purpose to protect the ecosystem from harmful chemicals, while the chemical community via the processes of green chemistry is geared towards developing novel compounds and processes that are safe for human health and the environment. Green or sustainable chemistry is a term related to the manufacture of chemical products and processes that decrease or eliminate the use and production of harmful materials. As a new branch of chemistry with ecological approaches it involves reducing or eliminating the use of harmful substances in chemical processes as well as dropping harmful and toxic products. In order to be called "green," each reaction should be having three green components: including reagent/catalyst solvent, and energy consumption. In addition, 
green chemistry is interested in the best form of waste disposal and designing the process of chemical products' degradation after use, all in accordance with pollution inhibition and sustainable progress measures [4,5]. Moreover, the concept of green chemistry has had this large impact because it goes beyond the research laboratory in isolation and has touched industry, environment, education, and the public. The field of green chemistry has established how chemists can synthesis next generation products and processes so that they are profitable while being good for both human health and the environment. As well as, the scientific enthusiasm of green chemistry, teaching initiatives, governmental funding, and the establishment of green chemistry research centers (CGRC) have multiplied in the past two decades. Several universities now offer classes on green chemistry and green engineering [4].

Likewise, the 12 principles of green chemistry are design principles that provide the framework for sustainable design. They constitute an overarching concept for the design of safer chemicals and chemical transformations. Chemistry has long been perceived as a hazardous science and often the public connections the word "chemical" with "toxic." There are methods to reduce risk by using safety precautions such as protective gear. When safety protections not success, the risk, which is defined as a function of the hazard and exposure, increases. If the hazard is high and exposure controls fail, the results can be catastrophic (death). By reducing the hazard portion of the equation instead of focusing only on exposure controls, the danger can be limited even in cases of undesirable circumstances such as accident, spills, and sabotage $[3,6,7]$.

Intrinsic hazard of a chemical substance or a chemical process can be designed to be reduced at every level of a process, whether it is toxicity, physical hazards like explosion, flammability or global hazards such as stratospheric ozone depletion. Risks based on these hazards may increase from the nature of the feedstock. Eliminate intrinsic hazards within chemicals and processes will be available with careful design, where a design based on the integration of the twelve principles as one cohesive set [3].

\section{The twelve principles}

The twelve principles of green chemistry were introduced by Paul Anastas and John Warner in 1998. They are a guiding framework for the design of new chemical products and processes, applying to all aspects of the process life-cycle from the raw materials used to the efficiency and safety of the transformation, the toxicity and biodegradability of products and reagents used. They were briefed recently into the more suitable and memorable acronym, productively $[3,8,9]$. The principles of green chemistry including. 


\section{Prevention of waste}

Prevention of waste is considered the first of the principles of green chemistry. It is healthier to prevent the formation of waste rather than to clean it up after the fact. The producing of any material that does not have realised value or the loss of unutilised energy can be known a waste. As mentioned above, waste can take many forms and may impact the environment differently based on its toxicity, its nature, its quantity, or the way it is released. For example, in 1992, the concept of what is now widely accepted as the $E$-factor, or environmental impact factor, was presented by Roger Sheldon [3-10]. This metric assistance to quantify the quantity of waste generated per kilogram of product. It is a means to assess the environmental acceptability of the manufacturing process.

The justification for the introduction of this principle is confirmed by the fact that around 12 billion tonnes of waste or about 300 million tonnes of hazardous waste for human health and the environment (so-called hazardous waste) are produced annually in the United States. The chemical industry produces $70 \%$ of the total amount of hazardous waste and the highest organic toxic waste (about 150,000 tons) with methanol and xylenes prevailing. Waste sanitation "consumes about $2.2 \%$ of gross US product, and costs continue to grow organic waste, which is harmful to humans, and the environment, is primarily produced at certain stages of synthesis. It is well-known those dirty reactions through using toxic reactants and solvents, and as a result of the harsh reaction circumstances, a large number of toxics by the products are produced. These are the most common basic reactions of organic synthesis (halogenation, oxidation, alkylation, nitration, and sulfonation) that are applied in different industrial branches [4-11]. Although the chemical industry, also other chemical manufacturers, have long ago avoided prevention, the attention of green chemistry is indeed to stop waste generation. However, the absolute prevention of waste generation in practice is virtually impossible since no input raw material can be fully utilized. In contrast, one waste disposed of illustrates the final loss of material goods in the circular flow: production-consumption. Therefore, any return of material goods to a circular stream represents a pure economic gain, and it is necessary to think first whether it is possible to prevent the generation of waste and if it is not necessary to devise how the amount of waste produced in production can be utilized in the best possible way, so it becomes useful [4-11].

\section{Atom economy}

In 1990 Barry Trost introduced the concept of synthetic efficiency: atom economy (AE) also known as atom efficiency $[12,13]$, which refers to the concept of maximizing the use of raw materials. For 
instance, the final product contains the maximum number of atoms from the reactants. The ideal reaction would incorporate all the atoms of the reactants. The $\mathrm{AE}$ is measured as the ratio of the molecular weight of the wanted product over the molecular weights of all reactants are used in the reaction (Figure 2). It is a theoretical value meant to fast assess how efficient a reaction will be [3].

$$
\text { The Atom Economy AE } A E=\frac{M W \text { of Product }}{M W \text { of reagents }}
$$

Example of a Grignard reaction

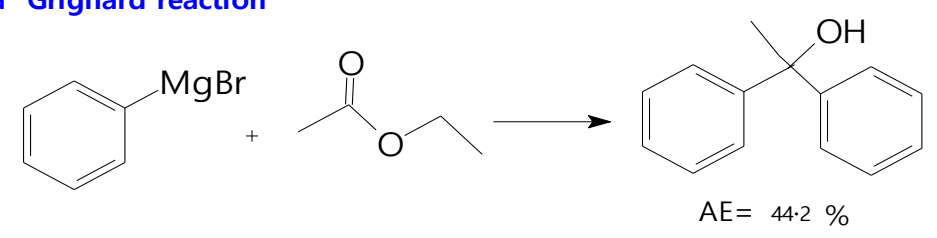

Applictions to the synthesis of propargylic amine
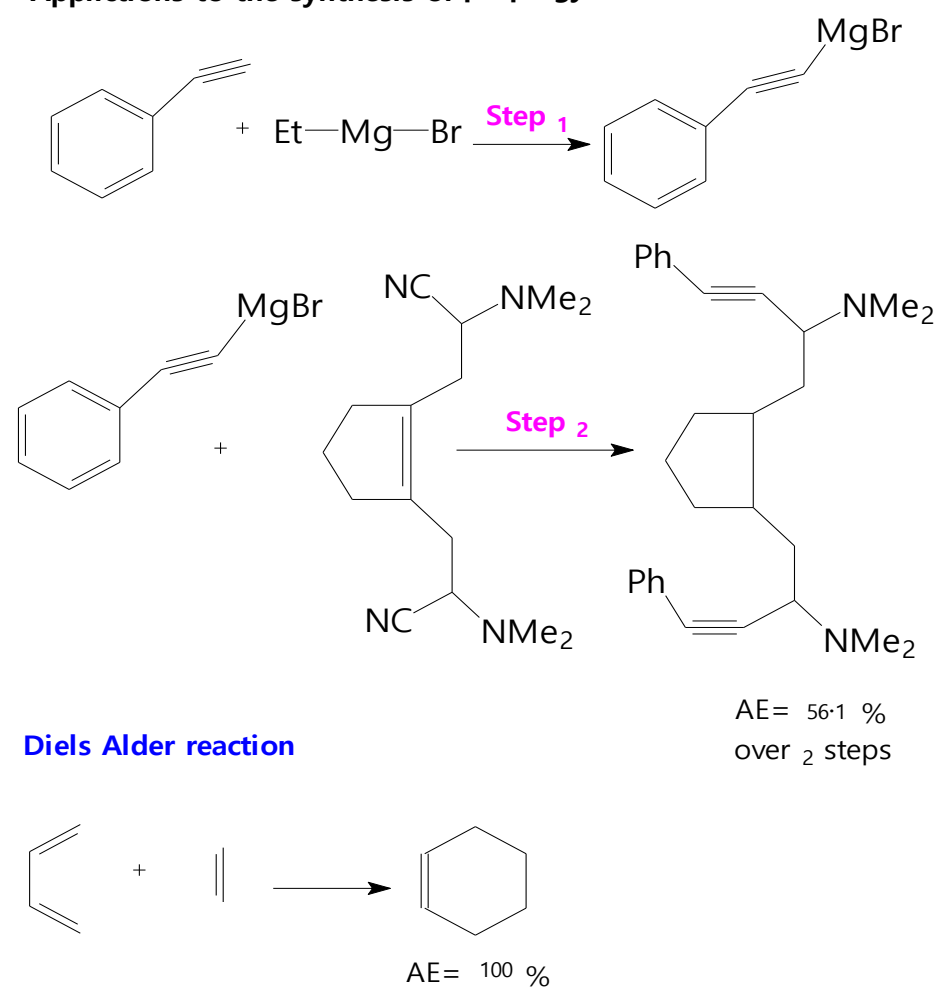

Figure 2. The atom economy AE and several demonstrations [3]

\section{Chemical synthesis for less hazardous}

Some of the new reactions that are developed in the past decade adding to the already existing green reactions. For example, reactions based on rearrangement cycloaddition or multi-component coupling 
reactions were already known and constitute one category of efficient reactions. Cascade or tandem reactions metathesis, $\mathrm{C}-\mathrm{H}$ activation, and enzymatic reactions are rather new approaches and demonstrate good examples of cleaner, more efficient synthetic tools available to organic chemists [3, 14-22].

Many industrial processes found cleaner and cheaper when harmful chemicals are replacing with biological enzymes [23]. For example, a new polycarbamate synthesis (PC) process is conceptually simple, based on the substitution of toxic carbonyl dichloride $\left(\mathrm{COCl}_{2}\right)$ with $\mathrm{CO}_{2}$. This procedure also consequences in the removal of dichloromethane $\left(\mathrm{CH}_{2} \mathrm{Cl}_{2}\right)$ as a solvent. The total reaction contains ethylene oxide $\left(\mathrm{CH}_{2}\right)_{2} \mathrm{O}, \mathrm{CO}_{2}$ and bisphenol $-A\left(\mathrm{C}_{15} \mathrm{H}_{16} \mathrm{O}_{2}\right)$ to produce polycarbamate and ethylene glycol $\mathrm{C}_{2} \mathrm{H}_{6} \mathrm{O}_{2}$ as shown below (Figure 3) [24, 25].

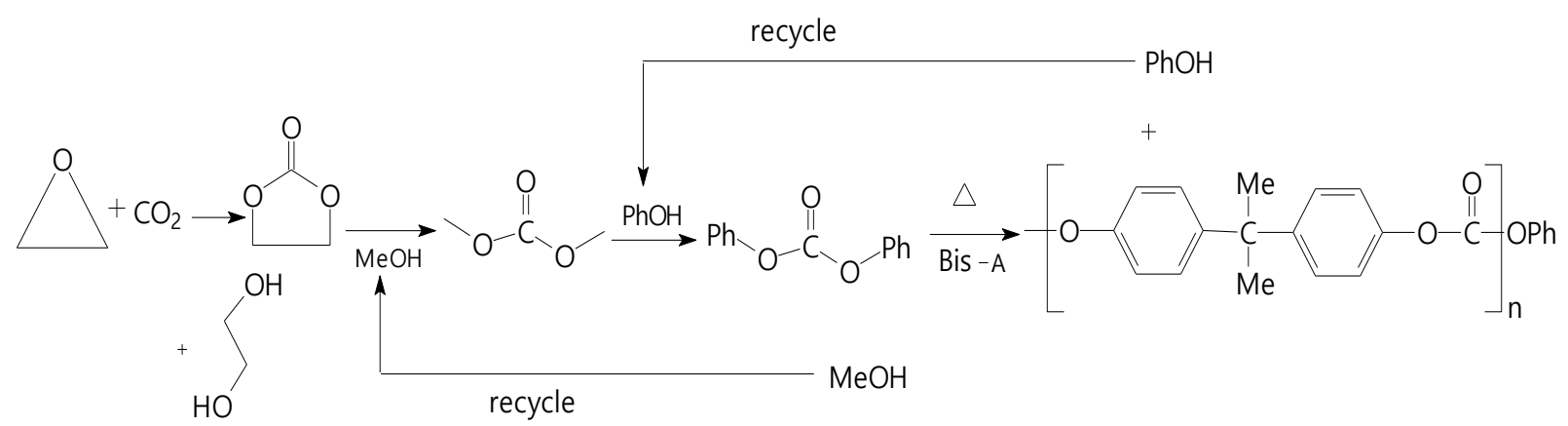

Figure 3. Synthesis of polycarbamate [25]

\section{Safe solvents}

The use of substances such as solvents and separation agents should be made needless wherever possible and innocuous when used. For example, chromatographic separations used large quantities of solvents, which are problematic causes of environmental pollution. Most traditional organic solvents are toxic, flammable and corrosive. Their recycling is connected to energy-efficient distillation with considerable losses [4]. For this reason, the development of environmentally-friendly solvents is required. Safer solvents recommends that the process of synthesis be maximally reduced and, whenever possible, avoid the use of auxiliary chemical substances and if they used should be harmless. According to the principles of green chemistry, the choice of suitable substitutions for organic solvents is based on process safety, worker safety, environmental safety and sustainability of the process. The solvent should be physically and chemically stable, low volatility, easy to use and easy to recycle [4, 2629]. 
Solvents are possibly the most active area of green chemistry research. They characterize an important challenge for green chemistry as they often account for the vast majority of mass wasted in synthesis and processes. Furthermore, several conventional solvents are toxic, flammable, and corrosive. Their solubility and volatility have contributed to air, water, and land pollution, which have increased the risk of workers' exposure, led to serious accidents. Recovery and reuse, when possible, is often connected with energy-intensive distillation and sometimes cross-contamination. To address all those shortcomings, chemists started a search for safer solutions. Solventless systems, water, supercritical fluids (SCF) and more recently ionic liquids are some of the examples of those new "green" answers [3, 30-33].

Where possible, the perfect situation would be not to use any solvent because the decision to include an auxiliary always implies efforts and energy in order to remove it from a designated system. Efforts have consequently been devoted to developing solventless systems. This idea was reinforced through the finding that solvents account for most of the industrial waste. Besides, based on the physical properties of the reagents used or the desired outcome of the transformation, the approach often needs a new or redesigned chemistry to let the reaction to proceed without the original solvent [3, 33-36].

Water is the most abundant molecule on the planet and is sometimes indicated as a benign universal solvent. Being able to run a reaction in water therefore has important advantages. Water as known is safe and does not pose any hazards, which can be a beneficial solvent for large scale processes in chemical reactions. The properties of water have even led to improved reaction rates via the hydrophobic effect and easier separation since a lot of organic substances do not dissolve in water. The case of an improved Diels-Alder reaction in water is one of the useful examples demonstrating the advantages of water as a solvent [3, 37-39]. One disadvantage which may slow down industrial applications and has yet to be addressed is the risk of water pollution that can be very energy-intensive to clean [3].

\section{Designing safer chemicals}

Chemical products should be designed in order to affect their needed function while lessening their toxicity. Minimizing toxicity, while keeping function and efficiency, can be considered one of the most challenging parts of designing safer products and processes, and achieving that aim requires understanding not only chemistry but also the principles of toxicology and environmental science. Moreover, the goal of producing safe chemicals (non-carcinogenic, mutagenic, and neurotoxic) is the equilibrium between optimal performance and chemical product function, confirming that toxicity and hazard are reduced to the lowest possible level. In other words, the use of toxic chemicals should be 
avoided and replaced inhospitable wherever possible however, should take account of their efficacy [4, 40]. This principle has used in the development of new insecticides and pesticides which are specific to target organisms, for instance, they are toxic only to target organisms and decompose into environmentally harmless substances. An additional example is the use of highly toxic organic tin-based organic compounds $(\mathrm{Sn})$, earlier coated on the outside to prevent the capture of seaweed and plankton. These organic compounds have been replaced by a non-toxic product called Sea-Nine. As well, an example is the development of oxidant activator for hydrogen peroxide. This allows the replacement of chlorine bleaches (preparations that damage the ozone layer) through hydrogen peroxide in paper production [23].

Another example is the production of polymers of polyphenylene sulfone (PPSU), which is nowadays widely used for indoor airplanes and it is also introduced in underground trains where it is a significant to use non-flammable materials. It is a new engineering plastic characterised by a novel combination of useful environmental, mechanical, and flame-resistant properties [4, 41].

\section{Design for energy efficiency}

Increasing concerns over the depletion of petroleum feedstocks and the growth in energy consumption have pushed the development of additional energy-efficient procedures and for the search for renewable energies; non-depleting resources in a time frame relevant to human scale [3, 42]. The energy requirements of chemical procedures should be recognised for their economic and environmental impacts. In 1973 the oil crisis has initiated the development of several processes in which energy savings are considered, to exploit every kJ of energy in the production process [4]. Unutilised energy may also be considered a waste. The design of chemical reactions that do not involve intensive energy use is highly desirable. Dropping the energy barrier of a chemical reaction or choosing suitable reactants so that the transformation may proceed at room temperature is one example of what chemists can do in order to reduce energetic requirements, with all the direct and indirect benefits accompanying with it. Rising the energy efficiency of a chemical system is purely one part of the solution. Alternative energies are wanted. Several of those renewable energies have been recognised in biofuels production, including solar power (thermal and photovoltaic), wind power, geothermal energy, hydropower, and hydrogen fuel cells. Green chemists have a significant role to play in this new challenge as known they can design both energy efficient transformations and chemical systems that can be used to harvest some of those renewable natural energies [43, 44].

Solar energy is considered the primary sustainable energy source on earth and is considered as an alternative to petroleum. Considerable efforts have been dedicated to designing chemical systems to 
convert solar radiation into voltaic energy. Also, organic, inorganic, and hybrid solar cells have paid attention due to their higher efficiency. The main principle of those cells depending on the ability of the material used to absorb photonic energy from solar radiation. The absorption causes the formation of excited states which can be relayed and generate electronic current. In the same word, building materials that can efficiently transform light into current remains a challenge and are key to the achievement of this approach $[3,45,46]$.

\section{Reduce derivatives}

Unnecessary derivatization such as blocking groups, temporary modification of physical/chemical processes, protection/deprotection should be reduced or avoided if probable, because such steps need extra reagents and lead to generate waste. The biological synthesis should be used if possible [4].

Developed a non-covalent protecting group in the form of a co-crystal between hydroquinones and bis$(\mathrm{N}, \mathrm{N}$-dialkyl)terephthalamides (Figure 4$)$, where this approach was viable and successful for the industrial process. It solved the problem without modification of the original hydroquinone structures and reduced both waste material and energy [3].

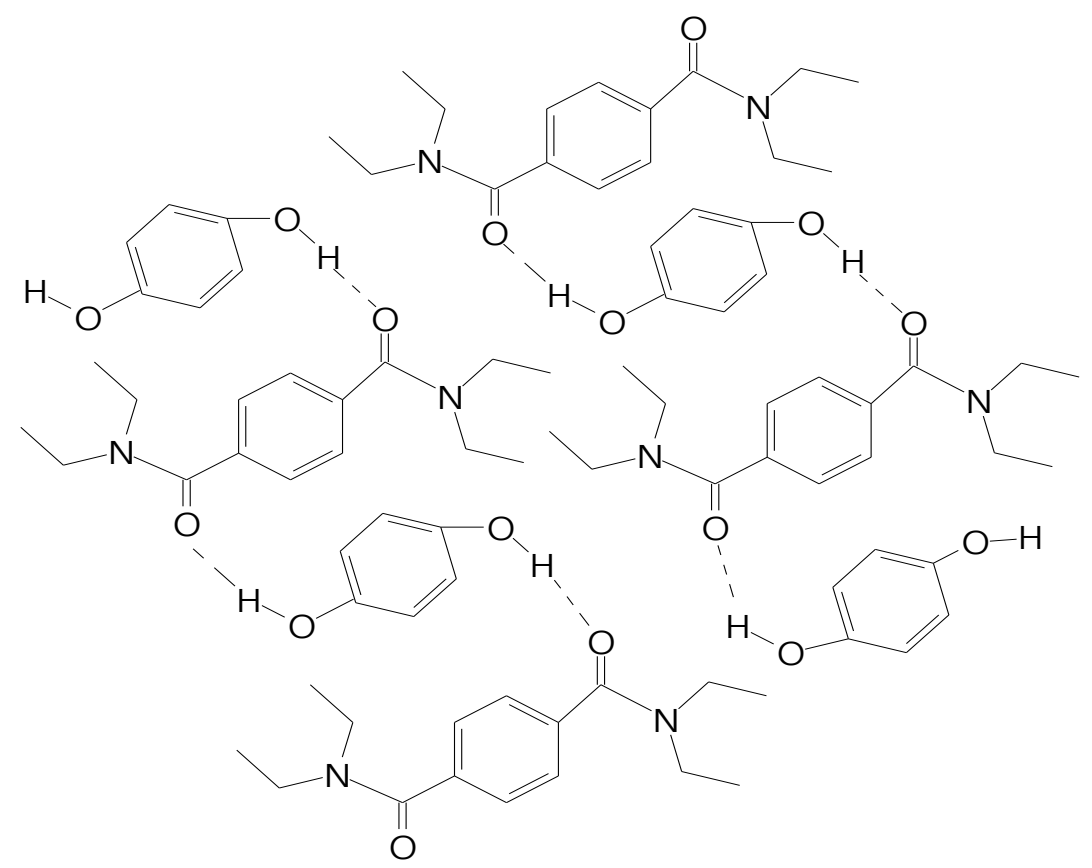

Figure 4. Illustrates 8 hydroquinones protected by non-covalent interactions with bis- $(N, N$ dialkyl)terephthalamides [3] 


\section{Catalysis}

Catalytic reagents are superior to stoichiometric reagents. As it is known that, in many cases, the formation of waste is linked to the traditional use of a stoichiometric amount of reagents $[3,4]$.

For environment protection, the catalysis principle encourages the use of biodegradable catalysts, which indicate less energy use, avoiding the use of organochlorine compounds and decreasing the use of less waste-water and less energy.

In addition, bio-catalysis is an example of green chemistry as it is a biomimetic approach based on natural or modified enzymes. It usually indicates both the direct use of purified enzymes and the transformations accomplished by engineered living organisms. Also, reaction conditions are quite mild as the transformation can be achieved in water at atmospheric pressure and ambient temperature. Likewise, enzymes have proven to be more stereochemistry, chemical selectivity. In addition, biocatalysts in comparison with non-biological catalysts, have a great advantage given the rate of reaction, lesser cost, catalytic specificity, etc, but lack of heat sensitivity and poor stability [3].

\section{Biodegradation}

Chemical products should be designed to break down into innocuous degradation products without causing any danger for the environment. The goal of creating degradable chemicals and products that, upon the termination of their activity, must be able to convert into harmless products to the environment. The aim is to prevent the formation of harmful substances and to return to production as much waste as possible, which is achieved via using recycling [3].

The problem of persistence has been known for a long time and became apparent in the primary stages of industrial development $[47,48]$. For instance, in the 1950s, tetrapropylene-alkylbenzene sulfonate (TPPS) was used as a surfactant for laundry detergents where it is accumulated into the water supply as a result of an unfinished degradation. The situation was so critical, where water tended to foam when coming out of the tap. The immediate solution was found to replacing the methyl branched chain of TPPS by a linear carbon chain that reduces bio-persistence.

Designing biodegradable materials and chemicals is no easy task as demonstrated by continuing problems of environmental pollution. Trends have emerged following decades of data collection. Some chemical structures such as branched chains, halogenated moieties, quaternary carbons, tertiary amines, and certain heterocycles may have enhanced persistence and are avoided. On the other hand, integrating functional groups like esters or amides which are recognised by ubiquitous enzymes may assistance the design of environmental degradable products $[48,49]$. 


\section{Analysis}

Green analytical chemistry can be defined as the use of analytical procedures that produce lesser waste and are safer for the environment and human health $[3,50]$. This definition includes both parts of live monitoring of a chemical transformation and the environmental shortcomings accompanying with traditional analysis.

The goal of green analytical chemistry is to measure chemicals without producing waste. The environmental issues related to analytical chemistry are typically linked to the analytical process itself. Products used in the manufacture of analytical apparatus should be taken into consideration. Both green engineers and green chemists building new sensors should be aware of the toxicity and any potential environmental difficulties associated with the material they handle. For example, mercury electrodes are often used for electrochemistry. The effective solution has proven by replacing them with carbon-based electrodes such as nanotubes or nanofibers $[3,51]$.

\section{Accident prevention}

Substances are used in a chemical process should be selected to minimize the possibility of chemical accidents, including releases, explosions, and fires. For example, the increasing use of supercritical $\mathrm{CO}_{2}$ that replaces organic solvents (not toxic or explosive and is friendly-environment). Safety is defined as a controlling of known hazards via achieving an acceptable level of risk and is achieved at some levels of the lowest use of personal protective equipment.

According to the chemical accident prevention and the clean air act amendments of 1990, avoiding accidents starts through identifying the hazards $[3,52]$. All kinds of hazards whether it is toxicity, physical hazards such as explosivity or flammability, and global hazards should be addressed in the design of chemicals and processes to prevent accidents like the love canal incident and Bhopal. This accident should be an initial reminder to the scientific community because many chemicals are still used to present serious hazards which should be replaced by safer alternatives in order to prevent accidents wherever possible.

\section{Use of renewable feedstocks}

One of the principles of green chemistry advocates the use of renewable feedstocks where it is economically and technically acceptable. For instance, it is suitable to use renewable raw materials instead of a variety of plastic materials, and at that point to waste away the waste materials. For this reason, the making of biodegradable plastic materials is a present trend. Biodegradable packaging has a future in the food industry. Many factors, including politics and changes in 
legislation, in addition to the global demand for food and energy resources, certainly affect the development of biodegradable packaging [53]. Over the past ten years, important progress has been made in the progress of fuels, chemicals, and materials from renewable raw materials. For instance, in the case of bioplastics, the use of renewable raw materials in manufacture positively affects energy consumption and $\mathrm{CO}_{2}$ emissions. Coca-Cola, a world-wide scale company, for the time being, makings bottles made of 30\% polyethylene (PE) blends, however American company nature works uses bottles have made from lactic acid polymers (PLA) made from lactic acid, obtained by fermentation of dextrose obtained from starch, most commonly corn [27].

\section{Disadvantages of green chemistry}

The basic task of green chemistry is designing chemical products and processes that reduce or eliminate harmful substances. This goal is also the biggest of green chemistry that is reflected in time, costs and lack of information. in specifical, converting from an old, traditional product to a new "green" product, design of a new product and process is often not easy and quite expensive, no known alternative chemical or raw material inputs, also there is a lack of unity on what is considered safe $[3,54]$.

With the high cost of implementation and the lack of information, that will lead to a lack of green chemistry where is no identified alternative in order to used chemical raw materials or alternative technologies for green processes. Moreover, there is also a lack of human skills. Ionic liquids are the future of green chemistry. Although there is no doubt that those are valuable in chemical synthesis. When applying 12 principles that define green chemicals, ionic liquids do not look principally green. While, as is well known, ionic liquids are slightly volatile due to the low vapor pressure, yet it is only one of the several things that make a substance green. For instance, ion-based, fluoro-anion-based and imidazole-based liquids are expected to be poisonous but cannot reach the environment through evaporation. The problem is that most ionic liquids are water-soluble and can simply reach the biosphere via that pathway $[4,54-56]$.

\section{Conclusion}

The goal of green chemistry as mentioned early is based on twelve principles which aim to reduce harmful materials from the production, and application of chemical products. It is well known that when designing a green chemistry process, it is impossible to find the requirements of all twelve principles of the process at the same time. Nevertheless, it attempts to apply as many principles as possible during certain steps of synthesis. The goal of green chemistry in both environmental protection and economic gain can be achieved via many directions. For instance, chemical products would be prepared so that at 
the end of their function was not persist in the environment and instead break down into unhurt degradation products.

As well as, the goals of green chemistry are as follows: to meet the wants of society in ways without harmful or depleting natural resources on earth which are the main objective of green chemistry. In this case, the focus is being shifted on manufacture products that can be fully reclaimed or re-used. Via changing patterns of production and consumption, steps are being taken to reduce pollution and waste, as one of the significant goals of green chemistry. It is critical to develop alternative technologies to prevent any further damage to health and the environment. It can be summarised that environmental conservation can be possible via the introduction of a green chemistry process. However, the green chemistry alone cannot solve the pressing environmental concerns and influences on our modern era but applying the twelve-principles of green chemistry into practice will finally help to pave the system to a world where the grass is greener.

\section{Conflict of Interest}

We have no conflicts of interest to disclose.

\section{References}

[1] Linthorst J.A. Foundat. Chem., 2010, 12:55

[2] Clark J., Chem. Br., 1998, 34:43

[3] Anastas P., Eghbali N. Chem. Soc. Rev., 2010, 39:301

[4] Ivanković A., Dronjić A., Bevanda A.M., Talić S. Int. J. Sustain. Green Ene., 2017, 6:39

[5] Valavanidis A., Vlachogianni T., Fiotakis K., International Conference "Green Chemistry and Sustainable development", Thessaloniki, 25-26/9/2009. Paper for Conference Proceedings, Thessaloniki, 2009

[6] Anastas P.T., Warner J.C. Green chemistry: Theory and practice, 1998, p 29-56

[7] Matlack, A. Introduction to green chemistry. CRC Press, 2010

[8] Tang S.L., Smith R.L., Poliakoff M. Green Chem., 2005, 7:761

[9] Tang S.Y., Bourne R.A., Smith R.L., Poliakoff M. Green Chem., 2008, 10:268

[10] Sheldon R.A. Green Chem., 2007, 9:1273

[11] Jukić M., Djaković S., Filipović-Kovačević Ž., Vorkapić-Furač J. Kem. Ind., 2004, 53:217

[12] Trost B.M. Science, 1991, 254:1471

[13] Trost B.M. Angew. Chem. Int. Edit. English, 1995, 34:259

[14] Jørgensen K.A. (Ed.) Cycloaddition reactions in organic synthesis. John Wiley \& Sons, 2002 
[15] Chiacchio U., Padwa A., Romeo G. Curr. Org. Chem., 2009, 13:422

[16] Smith M.B., March J., March's advanced organic chemistry: reactions, mechanisms, and structure. John Wiley \& Sons, 2019

[17] Knipe A.C., Watts W.E. (Eds.). Organic Reaction Mechanisms, John Wiley \& Sons, 1997

[18] Zhu J., Bienaymé H. (Eds.). Multicomponent reactions. John Wiley \& Sons, 2006

[19] Touré B.B., Hall D.G. Chem. Rev., 2009, 109:4439

[20] Dömling A. Chem. Rev., 2006, 106:17

[21] Jacobi von Wangelin A., Neumann H., Goerdes D., Klaus S., Struebing D., Beller M. Chem. A Eur. J., 2003, 9:4286

[22] Nicolaou K.C., Montagnon T., Snyder S.A. Chem. Commun., 2003, 2003:551

[23] Sheldon R. A., ACS Sustain. Chem. Eng.., 2017, 6:32

[24] Welton T. Proc. R. Soc. A, 2015, 471: 20150502

[25] Anastas P.T., Kirchhoff M.M., Williamson T.C. Appl. Catal. A General, 2001, 221:3

[26] Hoffert M.I., Caldeira K., Benford G., Criswell D.R., Green C., Herzog H., Lightfoot H.D. Science, 2002, 298:981

[27] Nampoothiri K. M., Nair N. R., John R. P., Bioresour. Technol., 2010, 101:8493

[28] Draths, K. M., Frost, J. W. in: Anastas, P. T., Williamson, T. C. (Eds.). Green Chemistry: Frontiers in Benign Chemical Syntheses and Processes, Ch. 9, Oxford University Press, New York, 1998, 150

[29] Williams, R. T. Human health pharmaceuticals in the environment: an introduction, Allen Press/ACG Publishing, 2005, 1

[30] Constable D.J., Curzons A.D., dos Santos L.M.F., Geen G.R., Hannah R.E., Hayler J.D., Webb R.L. Green Chem., 2001, 3:7

[31] Constable D.J., Curzons A.D., Cunningham V.L. Green Chem., 2002, 4:521

[32] Kerton F.M., Marriott R. Alternative solvents for green chemistry (No. 20). Royal Society of chemistry, 2013

[33] Tanaka K., Kaupp G. Solvent-free organic synthesis Weinheim: Wiley-VCH. 2003, 5

[34] Fujiwara Y., Jia C. Pure Appl. Chem., 2001, 73:319

[35] Labinger J.A., Bercaw J.E. Nature, 2002, 417:507

[36] Bergman R.G. Nature, 2007, 446:391

[37] Herrerias C.I., Yao X., Li Z., Li C.J. Chem. Rev., 2007, 107:2546

[38] Grubbs R.H. Tetrahedron, 2004, 60:7117

[39] DeSimone J.M. Science, 2002, 297:799

[40] Li C.J., Chan T.H. Comprehensive organic reactions in aqueous media. John Wiley \& Sons. 2007 
[41] Hill Jr H.W., Brady D.G. Polym. Eng. Sci., 1976, 16:831

[42] Laughton M.A., Renewable Energy Sources: Watt Committee: report number 22. CRC Press. 1990

[43] Babel W., Endo I., Enfors S.O., Fiechter A., Hoare M., Hu W.S., Stephanopoulos G., Advances in biochemical engineering/biotechnology. Cell., 2007, 107

[44] Foster R., Ghassemi M., Cota A. Solar energy: renewable energy and the environment. CRC Press. 2009

[45] Yüncü H., Paykoc E., Yener Y. Solar Energy Utilization: Fundamentals and Applications, Springer Science \& Business Media. 2012, 129

[46] Luque A., Hegedus S. Photovoltaic science and engineering. Chichester: John Wiley \& Sons Ltd., 2003

[47] Carson R. Silent Spring Houghton Mifflin. Boston, MA. 1962

[48] Boethling R.S., Sommer E., DiFiore D. Chem. Rev., 2007, 107:2207

[49] Nendza M. Structure-Activity Relationships in Environmental Sciences, Springer Science \& Business Media, 2012, 6

[50] Keith L.H., Gron L.U., Young J.L. Chem. Rev., 2007, 107:2695

[51] Rocha F.R., Nóbrega J.A., Fatibello Filho O. Green Chem., 2001, 3:216

[52] Stellman J.M. (Ed.). Encyclopaedia of occupational health and safety. International Labour Organization. 1998, 3

[53] Ivankovic A., Zeljko K., Talic S., Bevanda A.M., Lasic M. Arch. Lebensmittelhyg., 2017, 68:26

[54] Bhardwaj M., Neelam N. J. Basic Appl. Eng. Res., 2015, 2:1957

[55] Clarke C.J., Tu W.C., Levers O., Brohl A., Hallett J.P. Chem. Rev., 2018, 118:747

[56] Schuur B., Brouwer T., Smink D., Sprakel L.M. Current Opin. Green Sustain. Chem., 2019, 18:57

How to cite this manuscript: Wanisa Abdussalam-Mohammed*, Amna Qasem Ali, Asma 0. Errayes, Green Chemistry: Principles, Applications, and Disadvantages. Chemical Methodologies 4(4), 2020, 408-423. DOI:10.33945/SAMI/CHEMM.2020.4.4. 